\title{
AVALIAÇÃO DA PERCEPÇÃO DO USUÁRIO UTILIZANDO O MÉTODO RGT: Análise de escovas de dentes
}

\author{
EVALUATION OF THE USER'S PERCEPTION USING THE RGT \\ METHOD: toothbrushes analysis
}

\author{
DEMAISON, ANDRÉ \\ Doutorando em Design pela Universidade Estadual de São Paulo (UNESP) \\ demaison@gmail.com
}

FERRO, LARISSA

Graduanda em Arquitetura e Urbanismo pela Universidade Estadual do Maranhão (FAU/UEMA)

larissaferro.dg@gmail.com

FRANCO, MARISA

Graduanda em Informática Biomédica (UFPR)

marisafranco@gmail.com

\section{PASCHOARELLI, LUIS CARLOS}

Professor Titular da Universidade Estadual Paulista (UNESP)

luis.paschoarelli@unesp.br

\begin{abstract}
RESUMO
Com este trabalho, pretendeu-se compreender como ocorre a percepção estabelecida entre usuárioproduto mediante estudo de caso das escovas dentais a partir da aplicação do método RGT - Repertory Grid Technique -, proposto por Kelly (1955). Participaram da pesquisa onze participantes voluntários mediante apresentação e assinatura do TCLE, sendo seis estudantes do curso de Design e outros cinco alunos de outras áreas do conhecimento da Universidade Federal do Maranhão. Foram gerados 27 construtos, agrupados em oito dimensões construtivas, sendo três delas de caráter avaliativo. A partir da tabulação dos dados, foi possível realizar uma análise da percepção dos participantes a respeito das escovas dentais - indicando preferências, aceitação e rejeição, além de identificar os atributos que mais se destacaram positiva e negativamente. Foi possível inferir ainda que o repertório dos indivíduos influencia na percepção acerca do objeto estudado. Os resultados obtidos demonstram a viabilidade da aplicação do RGT para estudos de Design de Produto e apresentam inúmeros desdobramentos para a presente pesquisa.
\end{abstract}

RGT, Escovas de dentes, Design, Metodologia, Produto. 


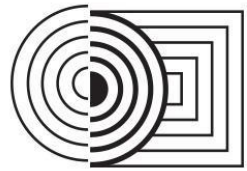

\section{$17^{\circ}$ ERGODESIGN \& USIHC 2019 \\ PUC-Rio, 11 a 13 de dezembro \\ Rio de Janeiro, RJ, Brasil}

$17^{\circ}$ Ergodesign - Congresso Internacional de Ergonomia e Usabilidade de Interfaces Humano Tecnológica: Produto, Informações Ambientes Construídos e Transporte

$17^{\circ}$ USIHC - Congresso Internacional de Ergonomia e Usabilidade de Interfaces Humano Computador

\begin{abstract}
This paper's objective was to understand, through a case study of toothbrushes using the RGT (Repertory Grid Technique) method proposed by Kelly (1995), how the perception established between user-product occurs. Eleven volunteers participated in the research upon presentation and signature of a consent form; six students of the Design course and five students from other fields of the Universidade Federal do Maranhão. 27 constructs were generated, grouped into eight constructive dimensions, three of them being evaluative. From the data tabulation, it was possible to perform an analysis of the perception respondents had of the toothbrushes - indicating preferences, acceptance and dislike, and identify the attributes that stood out positively and negatively. It was also possible to infer that the repertoire of individuals influences in the perception of the object studied. The outcome demonstrates the feasibility of applying the RGT method for product design studies and indicates numerous developments for this research.
\end{abstract}

RGT, Toothbrushes, Design, Methodology, Product.

\title{
1. INTRODUÇÃO
}

A diversidade dos mercados globais, associados às diferenças multiculturais dos consumidores, contribui para que os artefatos apresentem linguagens e características plurais, sendo este um dos fatores que contribui para que a competitividade no mercado seja cada vez maior (GOMES; CARVALHO; AMARAL, 2009).

É dentro desse contexto que o Design apresenta-se como importante característica de diferenciação e um dos principais recursos utilizados pelo setor produtivo (BÜRDEK, 2006), associado ao apelo advindo da interação emocional usuário-produto, no qual se considera uma relação em um nível mais profundo, para além dos interesses práticos e imediatos (GOMES; CARVALHO; AMARAL, 2009).

A partir dessas prerrogativas, o presente estudo propõe investigar a percepção humana acerca dos produtos, ou seja, tentar compreender por meio da utilização do Método Repertory Grid Technique - RGT (KELLY, 1955), como as propriedades dos objetos são percebidas pelos usuários e como esses elementos configurativos podem influenciar na tomada de decisão dos indivíduos. Para tal, realizou-se uma pesquisa com estudantes da área do Design e demais cursos da Universidade Federal do Maranhão. A aplicação do RGT foi realizada por uma equipe de alunos e professores do Fabrique Design - Núcleo de Prototipagem UFMA, pertencente ao curso de Design da Universidade Federal do Maranhão, e do Programa de pós-graduação em Design da Universidade Estadual Paulista (UNESP).

\section{FUNDAMENTAÇÃO TEÓRICA}

\subsection{A relação entre Percepção, Sensação e Design de Produto}

Para compreender como se estabelece a relação entre a percepção e a sensação, faz-se necessário compreender seus significados. Treismann (1998 apud KUNZLER, 2003, p.15) indica que a percepção "é a apreensão de uma situação objetiva baseada em sensações, acompanhada de representações e frequentemente de juízos (KUNZLER, 2003, p.15)". Consequentemente, a autora atribui à percepção a origem dos conhecimentos, que só se tornam possíveis a partir do pensamento e da linguagem. 


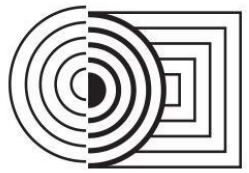

\title{
$17^{\circ}$ ERGODESIGN \& USIHC 2019 \\ PUC-Rio, 11 a 13 de dezembro \\ Rio de Janeiro, RJ, Brasil
}

$17^{\circ}$ Ergodesign - Congresso Internacional de Ergonomia e Usabilidade de Interfaces Humano Tecnológica: Produto, Informações Ambientes Construídos e Transporte

$17^{\circ}$ USIHC - Congresso Internacional de Ergonomia e Usabilidade de

Interfaces Humano Computador

Porém, outro aspecto que deve ser considerado dentro do âmbito da percepção, diz respeito à sensação. A sensação, por sua vez, é tida como:

\begin{abstract}
um fenômeno psíquico elementar que resulta da ação de estímulos externos sobre os nossos órgãos dos sentidos. As sensações podem ser externas, internas ou especiais. As externas são aquelas que refletem as propriedades e aspectos de tudo o que humanamente for perceptível e que encontramos no mundo exterior (KUNZLER, 2003, p.15)
\end{abstract}

Ao aproximar e relacionar os dois conceitos, Ballone (2001 apud KUNZLER, 2003, p.15) conclui que, para as pessoas ditas "normais", as sensações voltam-se predominantemente aos elementos neurofisiológicos, enquanto nas percepções os elementos psicológicos são os dominantes. "Cada órgão sensorial pode fazer inúmeras observações diferentes, intensidade da luz (variação), rugosidade de uma superfície, enfim, qualidades e quantidades percebidas nos objetos (KUNZLER, 2003, p.15)".

Essa avaliação sensorial, segundo Oliveira (2001 apud KUNZLER, 2003, p.15), é uma função primária inerente ao homem desde a infância e ocorre de forma mais ou menos consciente. Pode ser percebida ao aceitar ou rejeitar objetos, alimentos, sons, odores, cores e luzes; conforme a sensação que se experimenta ao observá-los.

Ainda segundo Oliveira (2001 apud KUNZLER, 2003, p.15), esta avaliação sensorial:

é a maneira mais precisa para catalogar estas percepções, ou seja, descobrir e quantificar as diferenças que podemos observar nos objetos, possibilitando assim identificar os limiares percebidos (diferença entre o estímulo físico padrão e a variável que será detectada).

A partir dessas prerrogativas decidiu-se buscar métodos que tornassem viável uma avaliação sensorial acerca dos produtos, para assim entender como se estabelece essa relação usuárioproduto. Por fim, procurou-se identificar possibilidades de melhorias e condições favoráveis ao desenvolvimento de produtos.

\subsection{O papel da Percepção Sensorial no Desenvolvimento e Uso de Produtos}

Kunzler (2003, p.16) indica que "a concepção de novos produtos está estreitamente relacionada com a percepção, desde que os usuários sejam considerados durante o projeto". Assim como Löbach (2001, p.159), que indica que os elementos configurativos dos produtos podem ser pensados para "alcançar efeitos pré-determinados nos usuários, provocando um "efeito emocional", a partir da influência exercida sob a sensibilidade e nas ideias dos usuários" (LÖBACH, 2001, p.160).

Esses elementos configurativos são agrupados em macroelementos e microelementos. Os primeiros são os que mais se relacionam com a percepção, pois são "aqueles que são aprendidos conscientemente no processo de percepção, como forma, material, superfície, cor, etc. através dos quais é determinada sua configuração, no essencial (LÖBACH, 2001, p.161)". Os microelementos, por conseguinte, são "aqueles que não aparecem de forma imediata no processo de percepção, mas que também participam da impressão geral da configuração" (LÖBACH, 2001, p.161). Baxter (2011, p.78), por sua vez, percebe a estética como aquela que "centra-se nas qualidades de estilo do produto que o torna atrativo", sendo que seu estilo é tido como fator primordial para provocar sua atratividade visual.

"A influência da escolha" dos indivíduos acerca dos objetos também pode ser explicada a partir da ótica do Design Emocional, proposto por Norman (2008), que apresenta três níveis: visceral, 


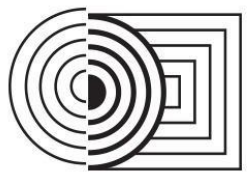

\section{$17^{\circ}$ ERGODESIGN \& USIHC 2019 \\ PUC-Rio, 11 a 13 de dezembro \\ Rio de Janeiro, RJ, Brasil}

$17^{\circ}$ Ergodesign - Congresso Internacional de Ergonomia e Usabilidade de Interfaces Humano Tecnológica: Produto, Informações Ambientes Construídos e Transporte

$17^{\circ}$ USIHC - Congresso Internacional de Ergonomia e Usabilidade de

Interfaces Humano Computador

comportamental e reflexivo. Para a presente pesquisa, foi necessário compreender os conceitos de Design Visceral e Comportamental, a fim de auxiliar na interpretação de alguns dos dados obtidos com a utilização do RGT.

\subsection{Escovas Dentais: características e evolução}

Conforme Barros, Pernambuco e Tomita (2001), a higiene bucal tem como preceito fundamental a fisioterapia oral correta, que segundo conceitos propostos pela Odontologia Preventiva, voltase ao controle da placa bacteriana a partir dos hábitos de higiene bucal (BARROS; PERNAMBUCO; TOMITA, 2001; VALDO, 2002, p.12). A escolha por analisar escovas de dentes deu-se por ser um objeto bastante importante do uso cotidiano, dessa maneira é possível inferir que todos os participantes podem ser potenciais usuários do produto.

A origem das escovas dentárias ainda é um assunto pouco relatado na literatura. Porém, são identificados relatos que mencionam os dedos, palitos, bastões, bolas de madeira com mel, pedaços de madeira aromatizados, enxaguatórios com vinho branco, toalhas de linho como indicações para limpeza dos dentes (DA CUNHA, 1993 apud VALDO, 2002, p.12). Somente a partir de 1880, perceberam-se inovações no processo industrial de confecção, como a utilização de plástico para os cabos, a adoção de celulóide, em 1900, e o acetato de celulose, em 1930. Somente em 1938, surgiu o nylon para substituir as cerdas de pêlos naturais, popularizando a comercialização e utilização das escovas.

Barros, Pernambuco e Tomita (2001) apresentam algumas tipologias de escovas dentais lançadas no mercado brasileiro que foram objetos de estudos em pesquisas, dentre elas, temos as escovas aromatizadas; termossensíveis; com marcadores para indicação do tempo de troca; de cabeça tripla; elétricas; monobloco; ecológicas; interdentais; unitufo; bitufo, sulcus e orthodontic; e, por fim, escovas para prótese total. Para a presente pesquisa, foram adotadas tanto as escovas dentais comuns quanto escovas para prótese total.

\subsection{O método RGT - REPERTORY GRID TECHNIQUE}

Gkouskos, Normark e Lundgren (2014) atribuem a origem do Método de Grid de Repertório (Repertory Grid Technique, ou RGT, no original em inglês) à Teoria de Construtos Pessoais (TCP) desenvolvida por George Kelly, em 1955. Seu objetivo principal consiste em demonstrar como as pessoas experimentam e interpretam suas experiências (HERNANDEZ, 2005) a partir dos acontecimentos e ações diárias, permitindo aos indivíduos criar seu próprio repertório de "construtos" (ENDERS; MENDES; HESKETH, 1983). Esse repertório, por sua vez, permite-os gerar expectativas e interpretar novos eventos, facilitando, assim, a tomada de decisões e auxiliando na compreensão do meio que os cerca (SOUSA, 2015).

Kelly acreditava que essa organização de eventos e acontecimentos só se torna possível a partir da percepção desses elementos por meio de atributos, que são organizados por cada pessoa em escalas bipolares, que expressam propriedades e seus opostos. É a partir daí que vem o conceito de "construtos pessoais" (FRANSELLA; BELL; BANNISTER, 2004).

Os construtos funcionam como categorias criadas a partir da relação entre as propriedades e seus opostos levantadas pelos participantes a partir de seus repertórios, formando as escalas bipolares. Posteriormente, esses construtos são categorizados em uma tabela em forma de 


\section{$17^{\circ}$ ERGODESIGN \& USIHC 2019}

PUC-Rio, 11 a 13 de dezembro

Rio de Janeiro, RJ, Brasil $17^{\circ}$ Ergodesign - Congresso Internacional de Ergonomia e Usabilidade de Interfaces Humano Tecnológica: Produto, Informações Ambientes Construídos e Transporte

$17^{\circ}$ USIHC - Congresso Internacional de Ergonomia e Usabilidade de Interfaces Humano Computador

grade para tabulação - por isso o "grid" em seu nome, gerando uma escala de avaliação e um sistema de classificação que permite ao pesquisador analisar o fenômeno estudado.

Diversos estudos relatam a aplicação do método RGT em avaliações de produtos, para mensurar as possíveis necessidades de motoristas/usuários de carros em futuros utópicos ou distópicos (GKOUSKOS; NORMARK; LUNDGREN, 2014), para identificar requisitos projetuais (HASSENZAHL; WESSLER, 2000) ou para investigar a experiência do usuário perante produtos tecnológicos (FALLMAN; WATERWORTH, 2010).

A aplicação do RGT, segundo Fallman e Waterworth (2010), apresenta-se como uma técnica útil quando se tem por objetivo extrair significados em diversos domínios. Isso pode ser atribuído à sua versatilidade e também à quantidade de informações geradas a partir de suas aplicações, que geralmente se apresentam como de extrema relevância para a área do Design (HASSENZAHL; WESSLER, 2000). Com sua aplicação, é possível realizar leituras dos fenômenos em tempo real, criando-se imagens ou mapas mentais que estruturam e dão sentido ao objeto de estudo apresentado aos participantes (MARSDEN; LITTLER, 2000).

\section{MATERIAL E MÉTODOS}

O presente estudo consistiu na aplicação do método RGT para avaliar escovas dentais. Inicialmente foi aplicado um pré-teste utilizando canetas como objeto de estudo, de modo a familiarizar os pesquisadores com o método e avaliar o protocolo. 
$17^{\circ}$ ERGODESIGN \& USIHC 2019

PUC-Rio, 11 a 13 de dezembro

Rio de Janeiro, RJ, Brasil $17^{\circ}$ Ergodesign - Congresso Internacional de Ergonomia e Usabilidade de Interfaces Humano Tecnológica: Produto, Informações Ambientes Construídos e Transporte

$17^{\circ}$ USIHC - Congresso Internacional de Ergonomia e Usabilidade de Interfaces Humano Computador

Figura 01. Escovas selecionadas e suas respectivas nomenclaturas pré-determinadas. Fonte: elaborada pelos autores.
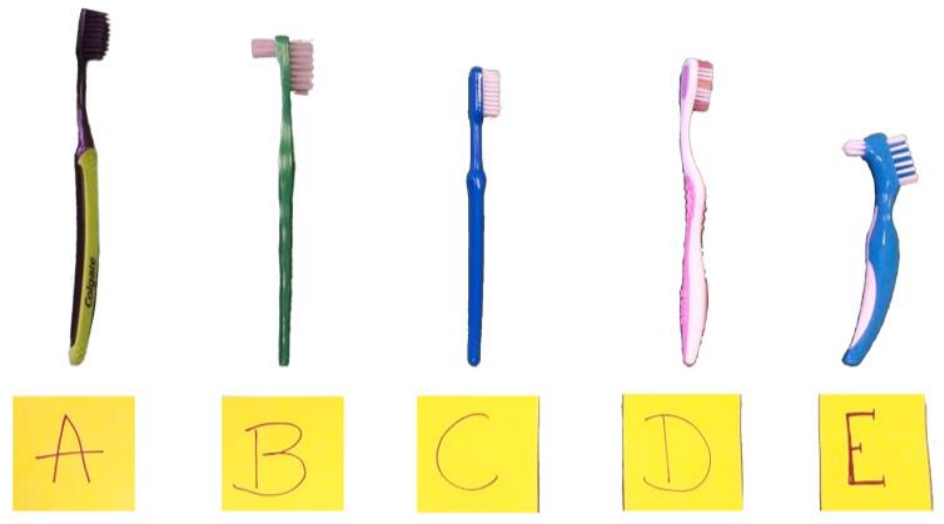

Para o teste, foram adotadas 5 tipos diferentes de escovas de dentes, a partir de discussões entre a equipe pesquisadora, considerando que todas deviam ter características claras que as diferenciassem umas da outras. As escovas foram nomeadas como "A", "B", "C", "D" e "E" (Figura 01).

Após nomeadas as escovas, determinaram-se todas as combinações triádicas possíveis: $A B C$, $A B D, A B E, A C D, A C E, A D E, B C D, B C E, B D E, C D E$. Em seguida, a partir do site "Random.org", a ordem de apresentação das escovas aos usuários foi randomizada, gerando uma ordem de apresentação a ser mostrada aos participantes.

Optou-se por uma amostragem não-probabilística, dividida em dois grupos: 10 (dez) estudantes de Design e 10 (dez) estudantes dos demais cursos da Universidade Federal do Maranhão, totalizando 20 participantes. Como procedimento inicial, foi apresentado e preenchido o Termo de Consentimento Livre e Esclarecido (TCLE) e, em seguida, o método foi aplicado, sem revelar quais aspectos seriam avaliados visando não influenciar nas respostas dos voluntários. O teste seguiu com a utilização do método triádico (GKOUSKOS; NORMARK; LUNDGREN, 2014; HERNANDEZ, 2009; FALLMAN, 2006; TOMICO et al., 2009), no qual, para cada trio apresentado aos participantes, esses deveriam identificar uma característica comum a dois dos três objetos, por meio de uma palavra ou expressão curta. Para cada propriedade gerada, os participantes deveriam propor um oposto nas mesmas condições. Esse processo foi repetido para todas as combinações.

Por fim, apresentou-se todas as escovas em conjunto e foi solicitado aos participantes que classificassem as 5 escovas dentro dos construtos criados, através de uma escala de avaliação de 0 a 5, conforme grid proposto pelo método (Figura 02). Deveriam ser consideradas as propriedades, seus opostos e pontuação atribuída para cada construto identificado nas escovas. 


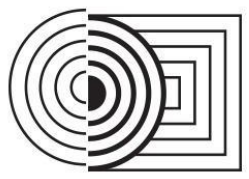

$17^{\circ}$ ERGODESIGN \& USIHC 2019

PUC-Rio, 11 a 13 de dezembro

Rio de Janeiro, RJ, Brasil $17^{\circ}$ Ergodesign - Congresso Internacional de Ergonomia e Usabilidade de Interfaces Humano Tecnológica: Produto, Informações Ambientes Construídos e Transporte

$17^{\circ}$ USIHC - Congresso Internacional de Ergonomia e Usabilidade de Interfaces Humano Computador

Figura 02. Aplicação do teste segundo o método RGT. Fonte: elaborado pelos autores.
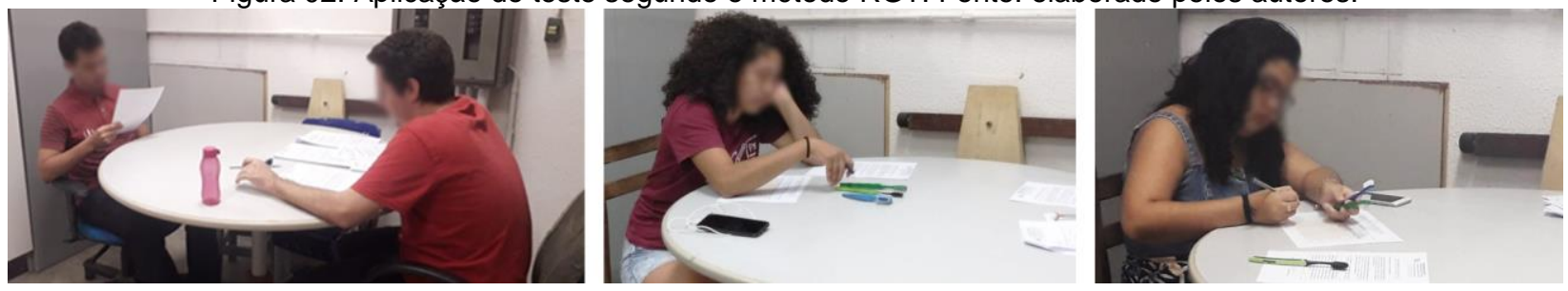

Os grids foram então transferidos para uma planilha a fim de gerar a análise e tabulação dos dados, permitindo assim a discussão das informações por parte da equipe. Os dados analisados foram de suma importância para entender a percepção dos usuários sobre as escovas dentais.

\section{RESULTADOS E DISCUSSÕES}

Inicialmente, o teste se daria com 20 participantes, sendo 10 alunos do curso de Design e 10 de outros cursos da Universidade Federal do Maranhão. Porém, alguns testes precisaram ser invalidados devido a falhas no procedimento de coleta de dados, como instruções inadequadas, indução de respostas ou falta de entendimento do participante.

Ao final, restaram 11 (onze) testes válidos: 6 (seis) participantes do curso de Design e outros 5 (cinco) alunos de outras áreas do conhecimento (Gráfico 01). Para o grupo do curso de Design foram ouvidos 2 (dois) indivíduos do sexo masculino e 4 (quatro) do sexo feminino. Já para o grupo composto por outros cursos, foram ouvidos 4 (quatro) indivíduos do sexo masculino e 1 (um) do sexo feminino.

Gráfico 01. Relação entre os cursos e sexo dos participantes. Fonte: elaborado pelos autores.

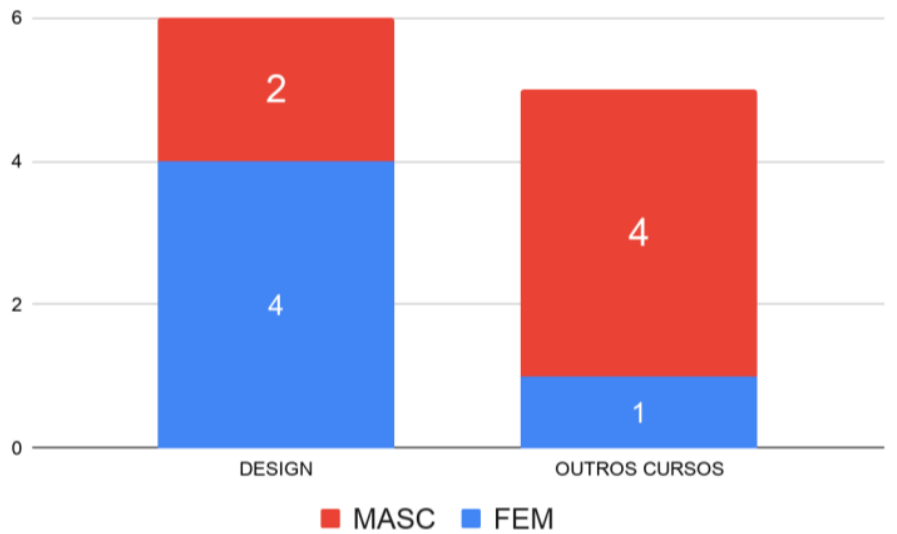

Devido ao baixo volume da amostragem, compreende-se que, para uma avaliação mais conclusiva das escovas dentais e da diferença de percepção entre os sujeitos, é necessária a refação do teste, com alterações no protocolo de procedimento e uma amostragem estatística mais expressiva, feita a partir de um recorte mais representativo.

Os grids RGT respondidos pelos voluntários foram transcritos para uma tabela, elaborada no Google Planilhas (Figura 03) com objetivo de visualizar melhor as propriedades, opostos e construtos e ainda possibilitar uma compreensão melhor da pontuação atribuída pelos usuários para cada construto. 
Figura 03. Recorte da planilha de sistematização do Protocolo RGT para tabulação. Fonte: elaborada pelos autores.

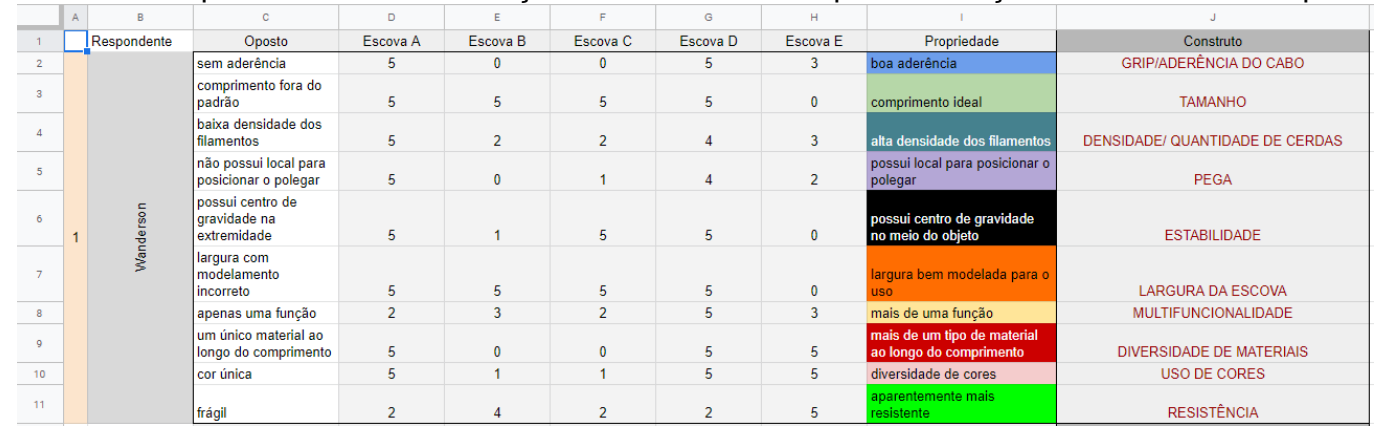

A elaboração da tabela possibilitou também uma primeira classificação por cores das propriedades elencadas. A mescla e a nomenclatura dos construtos, por sua vez, foram definidas a partir de uma discussão entre os pesquisadores. Por meio do senso comum, foi feito o agrupamento por similaridade, como também realizado por Gkouskos, Normark e Lundgren (2014). A partir dessa tabela, foram elaboradas outras três tabelas de frequência: uma para a frequência geral, outra para a frequência percebida para o grupo de estudantes de design e a última para o grupo de estudantes de outros cursos.

Assim, foi possível determinar as "dimensões construtivas" e avaliá-las como descritivas ou avaliativas (HASSENZAHL; WESSLER, 2000; GKOUSKOS; NORMARK; LUNDGREN, 2014). Os 110 construtos gerados foram mesclados por similaridade e transformados em 27, sendo encontrados 9 do tipo avaliativos e outros 14 descritivos, além de 4 que ficaram como "predominantemente descritivos" por não ter sido possível concluir se cabiam em uma das outras classificações. Por fim, os 27 construtos foram agrupados em 8 dimensões construtivas (avaliativas, descritivas ou, no caso da estética, predominantemente descritiva).

Percebe-se que, ao aplicar o RGT "às cegas", os participantes fizeram uma avaliação mais generalista da escova, destacando o que, de fato, estava mais evidente sem a necessidade do uso. Sendo assim, algumas dimensões construtivas foram mais relatadas dentre os participantes (Gráfico 02), como é o caso da "utilização da escova" - equivalente a $24,77 \%$ das menções, seguida das "cerdas" - com 18,35\%, cabendo às dimensões "estética" e "dimensionamento" um empate em terceiro com $15,60 \%$. 


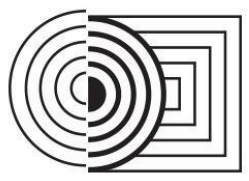

\section{$17^{\circ}$ ERGODESIGN \& USIHC 2019 \\ PUC-Rio, 11 a 13 de dezembro \\ Rio de Janeiro, RJ, Brasil}

$17^{\circ}$ Ergodesign - Congresso Internacional de Ergonomia e Usabilidade de Interfaces Humano Tecnológica: Produto, Informações Ambientes Construídos e Transporte

$17^{\circ}$ USIHC - Congresso Internacional de Ergonomia e Usabilidade de Interfaces Humano Computador

Gráfico 02. Frequência das dimensões construtivas relatadas pelos estudantes de design, de outras áreas do

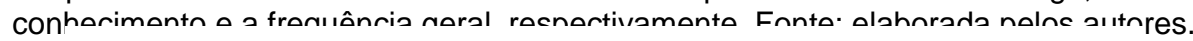

PORTABILIDADE

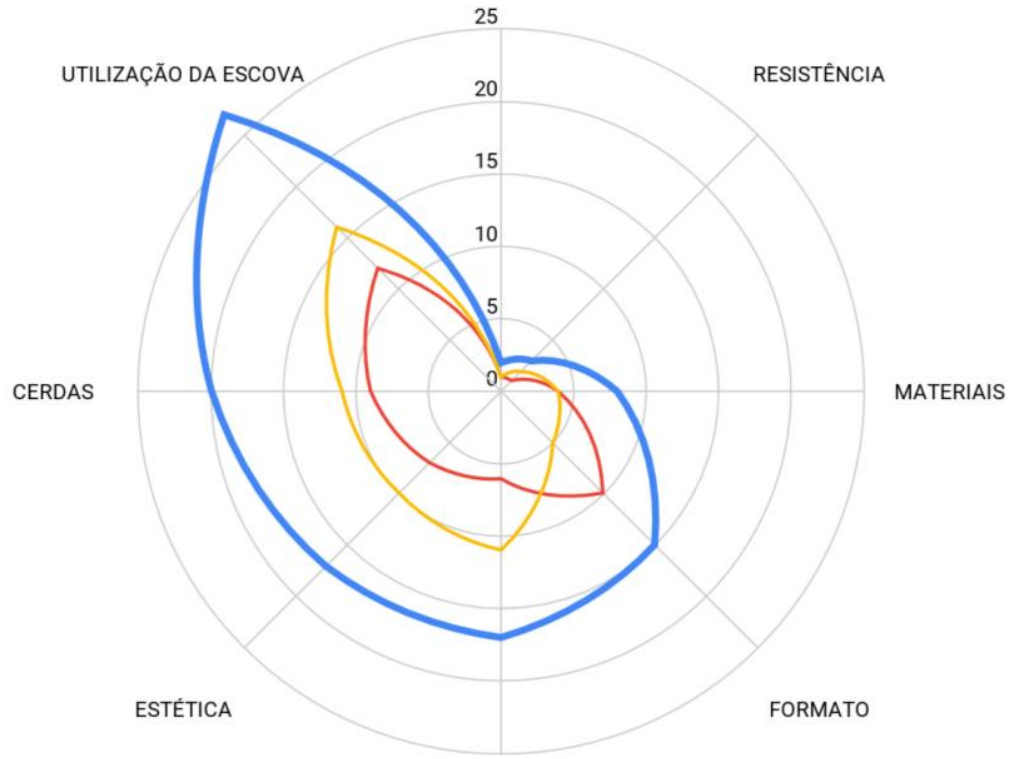

DIMENSIONAMENTO

- NDE MENÇÕES - MENÇÕES DE OUTROS CURSOS - MENÇÕES DO CURSO DE DESIGN

Sob essa ótica, é possível deduzir que, mesmo aplicando um teste que não possibilitava a utilização das escovas dentais, os participantes destacaram a dimensão construtiva "uso da escova". Tal observação corrobora uma das hipóteses iniciais, considerada ao definir o produto a ser analisado, por ser algo presente no cotidiano dos indivíduos de modo geral. Mesmo não utilizando os produtos, os participantes recorreram aos seus repertórios e experiências pessoais para realizar as avaliações. Isso pode apresentar-se como um indicador de que o método pode ser utilizado para muitas outras análises além da estética - considerando também, as funções práticas dos produtos, usualmente só percebidas completamente após a compra (LÖBACH, 2001). Fica evidente aqui, também, a importância da percepção sensorial no contato com o produto.

Outra questão que merece destaque é que, por meio do RGT, foi possível identificar que alguns construtos são passíveis de classificações "positivas" e outros "negativas", de acordo com o modo como o grid é respondido. A partir desse pressuposto, deduz-se que os construtos podem indicar "aceitação" ou até mesmo "recusa" ou "baixa aceitação", aspectos considerados para a avaliação dos dois grupos de participantes. A partir dessa observação, considerou-se pertinente a elaboração de uma pontuação (Gráficos 03 e 04) que possibilitasse uma avaliação mais detalhada e isolada a acerca do desempenho dos produtos a partir das dimensões relatadas pelos usuários.

Gráficos 03 e 04. Pontuação atribuída por escova pelos estudantes de design e de outras áreas do conhecimento, respectivamente. Fonte: elaborada pelos autores. 


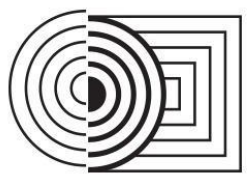

\section{$17^{\circ}$ ERGODESIGN \& USIHC 2019}

PUC-Rio, 11 a 13 de dezembro

Rio de Janeiro, RJ, Brasil $17^{\circ}$ Ergodesign - Congresso Internacional de Ergonomia e Usabilidade de Interfaces Humano Tecnológica: Produto, Informações Ambientes Construídos e Transporte

$17^{\circ}$ USIHC - Congresso Internacional de Ergonomia e Usabilidade de Interfaces Humano Computador
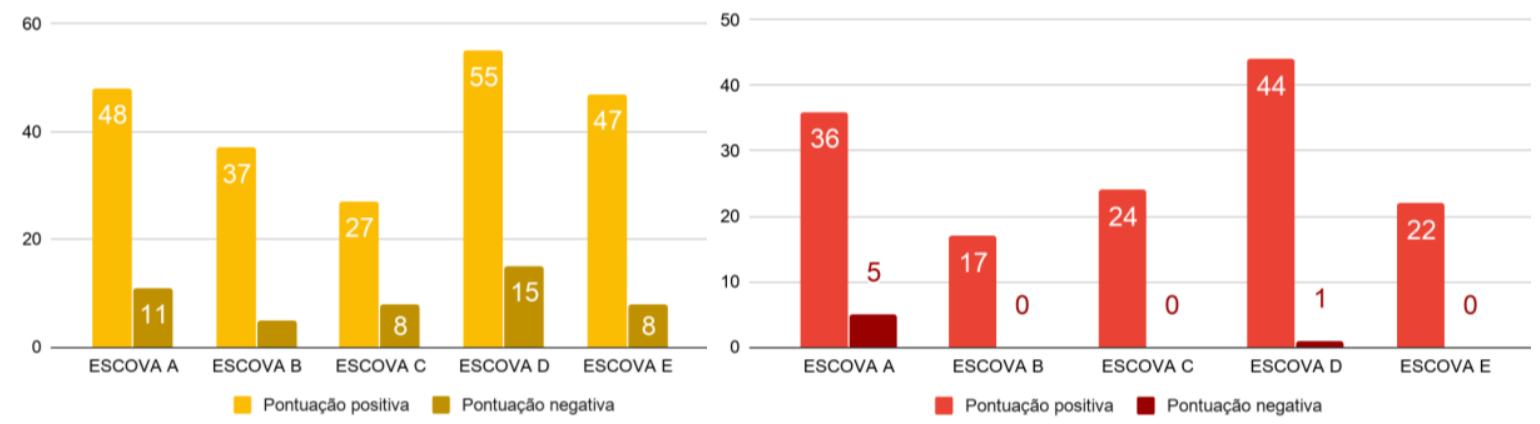

Nota-se que, entre os estudantes de design, houve uma maior aceitação entre as escovas $A, D$ e E. Em contrapartida, ao avaliar as escovas com pontuações negativas mais elevadas, também encontram-se as escovas $D, A$ e, empatadas, as escovas $C$ e $E$. Ao se observar as dimensões construtivas avaliadas pelos estudantes dos outros cursos, percebeu-se uma preferência pelas escovas $\mathrm{D}, \mathrm{A}$ e $\mathrm{C}$. Já os atributos negativos foram mais listados nas escovas A e D.

Para compreender quais aspectos foram considerados ao pontuar essas escovas, deve-se investigar as dimensões construtivas definidas como de caráter avaliativo, sendo elas: portabilidade, resistência e utilização da escova, com um total de 9 (nove) construtos.

Ao se comparar as respostas entre os dois grupos de estudo (Gráficos 05 e 06), percebe-se que ambos atribuíram mais características positivas à utilização das escovas e também à portabilidade.

Gráficos 05 e 06. Pontuações positivas atribuídas as dimensões avaliativas pelos estudantes de design e dos demais cursos, respectivamente. Fonte: elaborado pelos autores.

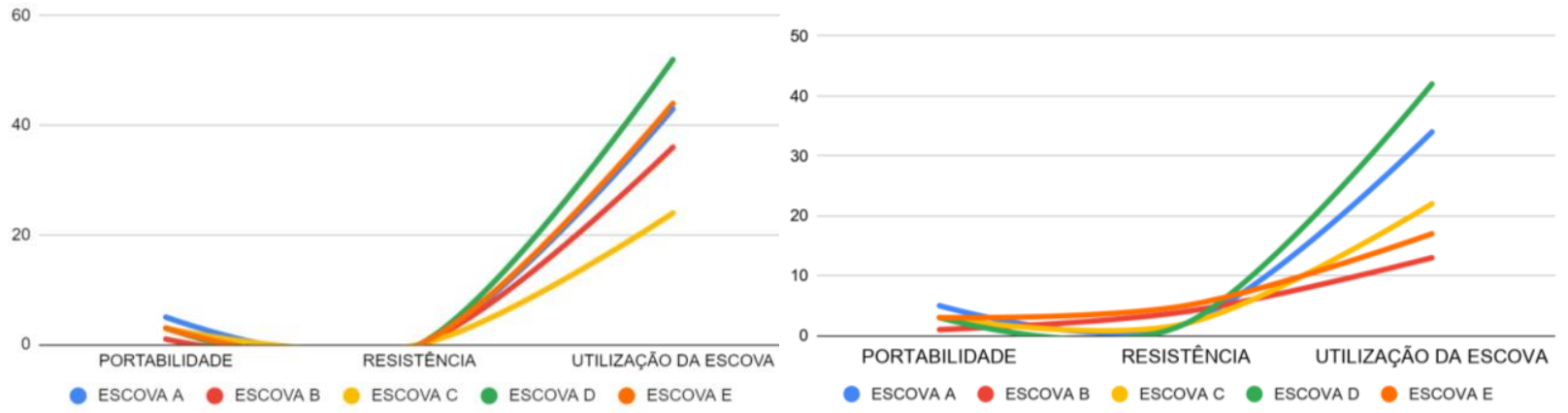

Já ao se comparar as respostas negativas utilizadas entre os dois grupos de estudo (Gráficos 07 e 08), percebe-se que os estudantes de design mencionaram as três dimensões, com maior destaque em pontos negativos para "utilização da escova". 


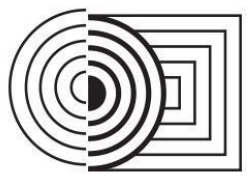

\section{$17^{\circ}$ ERGODESIGN \& USIHC 2019 \\ PUC-Rio, 11 a 13 de dezembro \\ Rio de Janeiro, RJ, Brasil}

$17^{\circ}$ Ergodesign - Congresso Internacional de Ergonomia e Usabilidade de Interfaces Humano Tecnológica: Produto, Informações Ambientes Construídos e Transporte

$17^{\circ}$ USIHC - Congresso Internacional de Ergonomia e Usabilidade de

Interfaces Humano Computador

\section{Gráficos 07 e 08. Pontuações negativas atribuídas às dimensões avaliativas pelos estudantes de design e dos} demais cursos, respectivamente. Fonte: elaborado pelos autores.
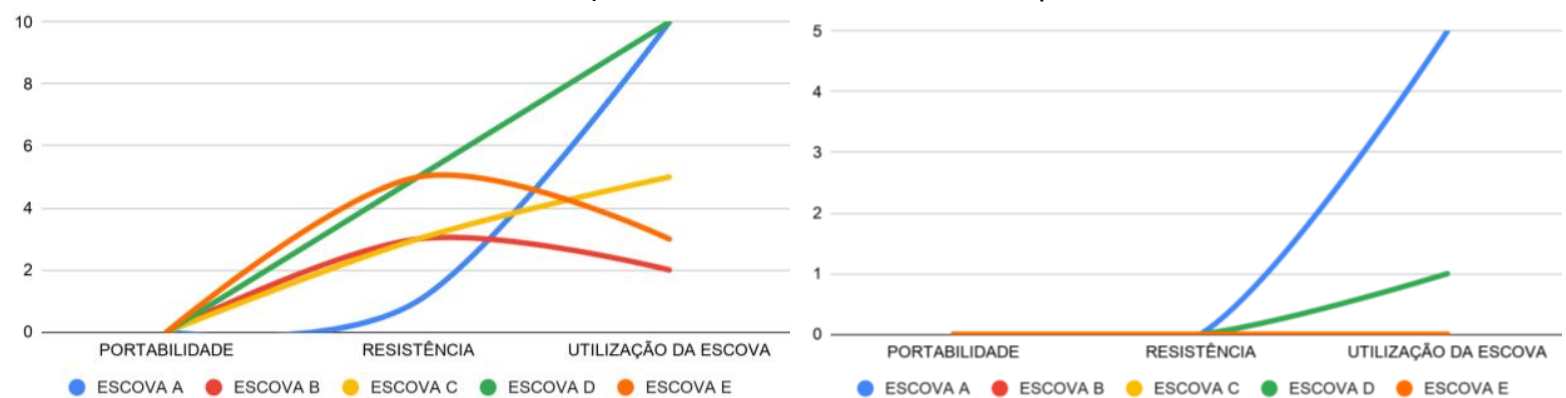

Percebe-se, com isso, que os designers fizeram uma avaliação mais criteriosa com relação às dimensões construtivas avaliativas, atribuindo pontuações bastante diversificadas para cada modelo. Tal fato se diferencia da avaliação do grupo composto por alunos de outros cursos, que destacaram as escovas A e D, especialmente sob a ótica da resistência e utilização da escova.

\section{CONCLUSÕES}

Considerando apenas as dimensões construtivas, foi possível posicionar cada uma das 5 escovas em espectros gráficos. A partir da visualização dessas informações foi possível perceber que não necessariamente o fato de um produto obter pontuação máxima na escala de avaliação significa ser bom ou ruim (nos construtos descritivos), especialmente quando se avalia a partir da ótica do indivíduo. O que se consegue perceber com esses indícios é que existem preferências por determinadas dimensões construtivas em detrimento a outras, fato que permite ao pesquisador inferir se um produto possui melhor ou pior aceitação entre os participantes do que o outro.

Dentre os principais objetivos estabelecidos com a aplicação do RGT neste estudo, pode-se elencar a intenção de extrair o máximo de informações possíveis com relação aos produtos analisados a partir da percepção do usuário. Fato que também foi um determinante para a escolha dos estudantes de design - que, em teoria, devem ter maior facilidade ao descrever atributos ou visualizar produtos em decorrência de seu olhar mais técnico e treinado para a tarefa em comparação com estudantes de outras áreas do conhecimento.

\section{REFERÊNCIAS bibliográficas}

ALVES, Castro. Navio negreiro. [S. I.]: Virtual Books, 2000. Disponível em: http://www.terra.com.br/ virtualbooks/freebook/port/Lport2/navionegreiro.htm. Acesso em: 10 jan. 2002.

BARROS, Olavo Bergamaschi; PERNAMBUCO, Renata de Almeida; TOMITA, Nilce Emy. Escovas dentais. Faculdade de Odontologia de São José dos Campos, São José dos Campos, v. 4, n. 1, p.32-37, jan/abr 2001. Quadrimestral.

BAUMAN, Zygmunt. Globalização: as conseqüências humanas. Rio de Janeiro: Jorge Zahar, 1999.

BALLONE, G. J. Percepção e Realidade: Curso de Psicopatologia, Parte 1 e 2. 2001.

Disponível em: <http://www.psiqweb.med.br/cursos/percep.html>. Acesso em: 13 set. 2019.

BRASIL. [Constituição (1988)]. Constituição da República Federativa do Brasil. Organizado 
por Cláudio Brandão de Oliveira. Rio de Janeiro: Roma Victor, 2002. 320 p.

BRASIL. [Constituição (1988)]. Constituição da República Federativa do Brasil de 1988.

Brasília, DF: Presidência da República, [2016]. Disponível em:

http://www.planalto.gov.br/ccivil_03/Constituicao/Constituiçao.htm. Acesso em: 1 jan. 2017

DICIONÁRIO ONLINE DE PORTUGUÊS. Percepção. Disponível em:

<https://www.dicio.com.br/percepcao/>. Acesso em: 13 set. 2019.

ENDERS, W. T.; MENDES, N. M. M.; HESKETH, J. L. A pesquisa de percepções individuais aplicada às áreas de administração e planejamento: conceitos, teoria $e$ metodologia. Revista de Administração da Universidade de São Paulo, v. 18, n. 1, 1983.

FALLMAN, D. Integrating User Experience into the Design Process with the Repertory Grid Technique: Some Preliminary Notes. WP9 Workshop on Innovative Approaches for Evaluating Affective Systems, Stockholm, Sweden, Jan 9-11, 2006.

FALMMAN, D.; WATERWORTH, J. Capturing User Experiences of Mobile Information Technology With The Repertory Grid Technique. in Human Technology, v. 6, n. 2., p. 250-268, 2010.

FRANSELLA, F.; BELL, R.; BANNISTER, D. A Manual for Repertory Grid Technique. Londres: Academic Press, 2003. ISBN 0470854901.

GKOUSKOS, D.; NORMARK, C. J. What Drivers Really Want: Investigating Dimensions in Automobile User Needs. in International Journal of Design, v. 8, n. 1, p. 59-71, 2014.

HASSENZAHL, M.; WESSLER, R. Capturing Design Space From a User Perspective: The Repertory Grid Technique Revisited. in International Journal of Human-Computer Interaction. Lawrence Erlbaum Associates, 2000. DOI 0.1207/S15327590IJHC1203\&4_13, v. 12, n. 3-4, p. 441-459.

HERNANDEZ, José M. A utilização do RGT (Repertory Grid Technique) na mensuração de imagem de shopping centers. RAI - Revista de Administração e Inovação, São Paulo, v. 2, n. 2, p. 19-32, 2005.

MARSDEN, D.; LITTLER, D. Repertory Grid Technique - An interpretive research framework, in European Journal of Marketing, v. 34, n. 7, p. 816-834, 2000. NORMAN, D. A. Design Emocional. Rio de Janeiro: Rocco, 2008.

OLIVEIRA, A.M.P. Laboratório de Análise Sensorial na Indústria de Alimentos: projeto e elaboração. Porto Alegre, 2001. 84p. Monografia - Instituto de Ciência e Tecnologia de Alimentos, Curso de Especialização em Ciência e Tecnologia de Alimentos da UFRGS. SOUSA, F. C. Percepção de Diferenças Atribuíveis ao Gênero dos Líderes na Promoção de Bem-Estar nas Empresas. Teoria e Prática em Administração, v. 5, n. 1, p. 105-129, 2015. TOMICO, O. et al. The Repertory Grid Technique as a Method for the Study of Cultural Differences. in International Journal of Design, v. 3, n. 3, p. 55-63, 2009.

TREISMANN, A. A atenção, os traços e a percepção dos objetos. Em ANDLER, D. Introdução às Ciências Cognitivas. São Leopoldo: UNNISINOS, 1998.

VALDO, Luiz Antonio. Escovas dentais convencionais: Um instrumento universal avançado de grande valia na prevenção da cárie e das doenças periodontais,. 2002. $36 \mathrm{f}$. Monografia (Especialização) - Curso de Odontologia, Faculdade de Odontologia de Piracicaba, Universidade Estadual de Campinas, Piracicaba, 2002. Disponível em:

$<$ http://www.bibliotecadigital.unicamp.br/document/?view=000778510>. Acesso em: 22 maio 2018.

\section{Agradecimentos}


O presente trabalho é parte das atividades do Projeto DINTER UFMA/UNESP e foi desenvolvido com apoio da Coordenação de Aperfeiçoamento de pessoal de Nível Superior - Brasil (CAPES); da Fundação de Amparo à Pesquisa e ao Desenvolvimento Científico e Tecnológico do Maranhão (FAPEMA - edital 012/2016, processo 04206/2016) e do CNPq (Processo 304619/2018-3). Agradecemos também à equipe do Núcleo de Prototipagem e Design (Fabrique) do CCET Centro de Ciências Exatas e Tecnologia da Universidade Federal do Maranhão. 